\title{
All-Lead-Flow-Batteries as Promising Candidates for Energy Storage Solutions
}

\author{
Michael Lanfranconi ${ }^{* 1}$, Hans-J. Lilienhof ${ }^{2}$ \\ ${ }^{1}$ Volterion GmbH, Carlo-Schmid-Allee 3, 44263 Dortmund, Germany \\ e-mail: michael.lanfranconi@ volterion.com \\ ${ }^{2}$ Department of Electrical Engineering, Westphalian University of Applied Sciences, Neidenburger Str. 34, \\ 45877 Gelsenkirchen, Germany \\ e-mail: hans-joachim.lilienhof@w-hs.de
}

Cite as: Lanfranconi, M., Lilienhof, H.-J., All-Lead-Flow-Batteries as Promising Candidates for Energy Storage Solutions, J. sustain. dev. energy water environ. syst., 7(2), pp 343-354, 2019, DOI: https://doi.org/10.13044/j.sdewes.d6.0256

\begin{abstract}
Soluble-lead-flow-batteries suffer from dendrite formation and thus shorting of the electrodes. Utilizing hexadecyltrimethylammonium-ion as an additive to the electrolyte, as well as periodic electrochemical renewal of electrode surfaces, the problem of dendrite formation has been eliminated. Laboratory scale cells have been designed and constructed that were able to cycle for more than 7,000 full cycles at $100 \%$ depth of discharge without intervention to the system. These cells have very high coulombic efficiencies of more than $97 \%$, as well as energy efficiencies of $70 \%$ and greater for each individual cycle. The strategy of in situ renewal of electrode surfaces at certain cycle intervals allows these cells to be reconditioned and start with new electrode surfaces each time such a maintenance is performed. Thus, these cells can be reset to their starting condition with each of these maintenance cycles.
\end{abstract}

\section{KEYWORDS}

Energy storage, Flow-battery, Lead, Soluble-lead-flow-battery, Electroplating.

\section{INTRODUCTION}

Electric energy harvested from solar, wind or hydropower is acknowledged to have little impact on the earth's climate and should therefore be utilized in a preferred manner to electricity obtained from combustion of fossil fuels with regard to its impact on $\mathrm{CO}_{2}$ emission and sustainability. However, due to the fluctuating and unpredictable nature of these sources, energy obtained in such a way needs to be stored in order to level out periods of low yields. Until storage systems are widely implemented, the electric grid still is very dependent on energy obtained from fossil fuels to maintain its stability [1].

Such storage facilities need to be able to have large capacities, high achievable cycle numbers and thus long operation times, while being able to cycle to low depths of discharge, and all at a reasonable cost. As electrical energy cannot be stored as such, except in capacitors, it generally has to be converted to some other form of energy in order to be stored and retrieved when needed. One method of storage is electrochemical storage, as employed in water-electrolysis or secondary batteries.

\footnotetext{
* Corresponding author
} 
Currently, lead-acid batteries are being widely used for residential storage of power from Photovoltaic (PV) plants in the range of up to several $\mathrm{kWh}$. While having an eminently low price and thus being very economic at small scales, their limitation in cycle life performance makes them non-ideal candidates for larger scale applications such as grid-stabilisation plants. Due to the lack of deep discharge ability and the rather short life of individual cells, such a system tends to have an increased service cost, elevating the price significantly. Soluble-Lead-Flow-Batteries (SLFB) are promising candidates for these large scale applications, as they solve many of the shortcomings of lead-acid batteries, such as poor deep cycle capability, low overall cycle life performance and high maintenance costs [2]. In addition to that, SLFB systems tend to be highly economic, they have an easy chemistry with only a single electrolyte and thus have a great improvement on energy density compared to other Redox-Flow-Battery (RFB) systems. As an ecological benefit, the methanesulfonic acid used in these batteries is non oxidising and has a high degree of biodegradability [3]. However, besides adhesion issues of lead dioxide on the positive electrode [4] as a common failure mechanism, lead has a tendency to deposit in a dendritic crystal form, which may eventually short the cell and require regeneration cycles for the cell to regain its performance. These dendrites have to be minimized in order for SLFB systems to enter the market of energy storage systems. It has been shown by the group of Meng et al. [5] that 2,000 cycles are possible in a laboratory beaker cell, however, these results have not yet been transferred to a flow cell. By adding suitable additives to the electrolyte and employing advanced charging techniques, as well as periodic renewal of electrode surfaces, laboratory flow-cells with high cycle numbers are shown to be feasible and thus smooth the way for economic and efficient energy storage systems. For examinations of deposit qualities, deposits formed from lead electrodeposition were characterized by Hull-cell experiments and Scanning Electron Microscopy (SEM), whereas full cell experiments were performed in laboratory scale modular flow cells, designed and constructed solely for this purpose. These flow-cells have an active surface area of $3.8 \mathrm{~cm}^{2}$ for each electrode respectively and are cycled at $20-40 \mathrm{~mA} \mathrm{~cm} \mathrm{~cm}^{-2}$ at $100 \%$ DoD. Additionally, periodic renewal of electrode surfaces has been implemented by fully stripping both electrodes to $0 \mathrm{~V}$. In these laboratory scale prototype setups, more than 450 full cycles were achieved at $40 \mathrm{~mA} \mathrm{~cm}^{-2}$, demonstrating the state of SLFB technology.

\section{Flow-battery-systems}

RFB, also named flow-batteries, are one promising approach of converting electrical energy to chemical bonding energy, so that the energy may be easily retrieved when needed with high efficiencies of up to $100 \%$. While classical batteries contain their active masses within the battery housing, their power and capacity are directly linked to each other. Power is determined by the active surface area and maximum current density of the electrode interface (separator between the two active masses), capacity is determined by the amount of electroactive species within the electrodes, which correlates directly to the thickness of the electrode. The inherent design constraints of batteries allow for very little variation of one parameter without affecting the other. Flow-batteries, however, consist of an electrochemical cell or rather a series (stack) of cells connected in a bipolar assembly (each cell is connected to its adjacent cell by means of an electrically conductive bipolar plate), employing a certain active surface area responsible for power, while the active masses are usually dissolved in an electrolyte and being stored within an external container. During charge or discharge of the system, fresh electrolyte is fed to the cell by means of pumps at an appropriate flow to allow electrochemical reactions at the electrode surfaces and at the same time removing reaction products. Such a system allows for much easier scaling of power and capacity as both variables may be scaled fully individually within a large range. Current flow battery systems are mostly based on 
vanadium compounds dissolved in sulfuric acid electrolyte Vanadium-Redox-Flow Battery (VRFB). Due to the relatively low solubility of vanadium-ions in the electrolyte, as well as the need for two separate electrolytes, each with its own pump and storage container, for the anode and the cathode, such systems are rather bulky and have a correspondingly low energy density of 20-25 Wh/L [6]. Additionally, for these systems in order to work properly, an ion exchange membrane is needed to keep the two electrolytes separated from each other, which adds further complexity and cost to the system.

Soluble-lead-flow-batteries. This type of flow-battery, also referred to as all-lead-flow battery, describes a form of a hybrid RFB system. While for most RFB systems all active masses are in a solvated state within the corresponding electrolyte at all times, a hybrid RFB system differs significantly as at least one of the electroactive species is being deposited onto the electrode substrate within the electrochemical cell. For an SLFB system, both active masses are plated onto the electrodes to form a solid film during charge of the battery, namely lead $(\mathrm{Pb})$ on the negative and lead dioxide $\left(\mathrm{PbO}_{2}\right)$ on the positive electrode. During discharge, both active masses are oxidised and reduced, respectively to their soluble form $\left(\mathrm{Pb}^{2+}\right)$ and dissolved within the Methanesulfonic Acidic (MSA) electrolyte. Since the surface of the electrochemical cell, opposed to other RFB systems, also plays a role in determining the capacity of the system, power and capacity may not be scaled fully independently from each other. However, there is still a lot more variation regarding different plating thicknesses for different use cases than for classical battery systems. The SLFB system has been extensively researched and described by Pletcher et al. [7-15] and there were prototypes built and tested in the past [14]. Still some major problems have not yet been overcome, so that this system is not ready for the market yet. SLFB, however, is a very promising candidate for a means of energy storage, as it has some significant benefits compared to other RFB Systems. For one, an SLFB system only needs a single electrolyte for both electrode reactions. Therefore, only one electrolyte reservoir, one pump and one set of pipes/tubing is needed (Figure 1). This also means that an ion exchange membrane or separator is redundant for such a system which significantly eases the system design and reduces the footprint by up to a factor of $50 \%$ compared to other RFB systems. In addition, the overall cell reaction involves a 2 electron transition as seen in eq. (1), which further increases energy density. As the active species has a very high solubility, an electrolyte of $50 \% \mathrm{~Pb}$ MSA (commercially available from chemical suppliers) has a theoretical energy density of more than $180 \mathrm{Wh} / \mathrm{L}$. A more practicable electrolyte containing $1 \mathrm{~mol} / \mathrm{L} \mathrm{Pb}$, still has $86 \mathrm{Wh} / \mathrm{L}$, which is more than two times the energy density of a single VRFB electrolyte and more than four times that of a VRFB system needing two electrolytes.

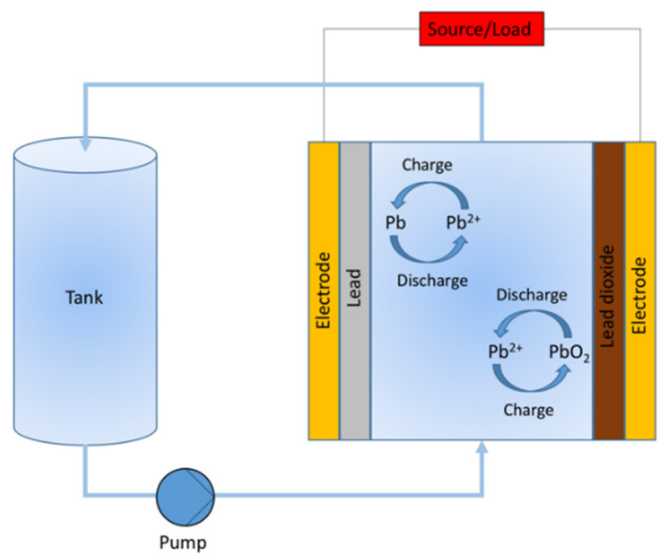

Figure 1. Schematic diagram of a SLFB-cell 


$$
2 \mathrm{~Pb}^{2+}+2 \mathrm{H}_{2} \mathrm{O} \underset{\text { Discharge }}{\stackrel{\text { Charge }}{\rightleftarrows}} \mathrm{Pb}+\mathrm{PbO}_{2}+4 \mathrm{H}^{+} \quad E^{0}=+1.544 \mathrm{~V}
$$

\section{MATERIALS AND METHODS}

All experiments were performed in a lab scale, using a battery tester BT-G-501 from ARBIN Instruments for full cell experiments and a battery test system from BaSyTec for pulse plating experiments. Full cell setups consisted of modular cells machined from acrylic glass (PMMA) with EPDM-rubber gaskets and Polypropylene (PP) fittings equipped with Polyvinylchloride (PVC) tubing (Figure 2). As a means of electrolyte circulation, a Watson-Marlow peristaltic benchtop pump was used with flow rate set to approx. $44 \mathrm{ml} / \mathrm{min}$. All full cells were cycled at $20 \mathrm{~mA} \mathrm{~cm}^{-2}$ or $40 \mathrm{~mA} \mathrm{~cm}^{-2}$ respectively, for both charge and discharge. End of charge was determined by a certain capacity $\left(20 \mathrm{mAh} \mathrm{cm}^{-2}\right)$ and end of discharge by a certain potential (1.1 V) (Table 1). Characterisation of additives was performed using a Hull-cell and applying a current of $5 \mathrm{~A}$ for $90 \mathrm{~s}$. As a counter electrode for lead deposition experiments, a pure lead cathode was used (Table 2). All experiments were performed at room temperature of approximately $295 \mathrm{~K}$. SEM pictures were taken using a HITACHI tabletop microscope TM3000. Electrolyte composition for all experiments was $1.0 \mathrm{~mol} / \mathrm{L}$ lead-methanesulfonate with $0.7 \mathrm{~mol} / \mathrm{L}$ methanesulfonic acid added as described by Meng et al. [5].

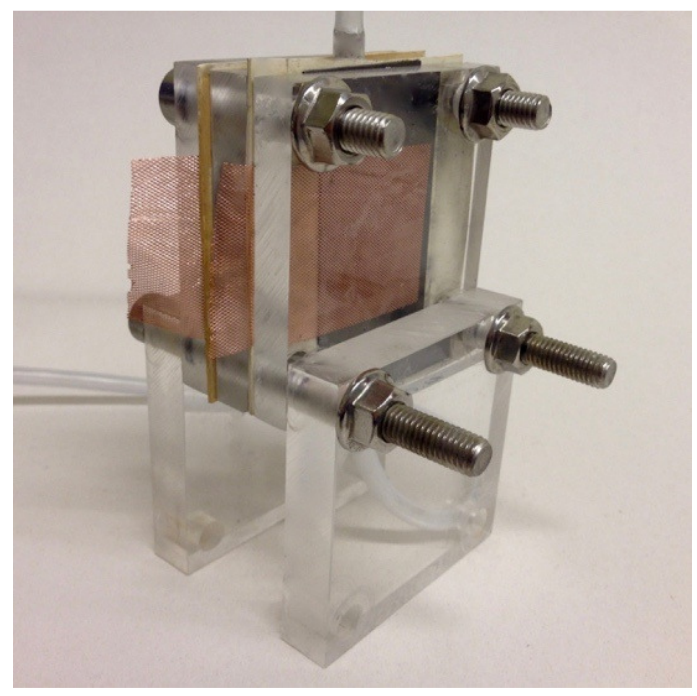

Figure 2. Acrylic test cell with electrolyte inlet at bottom and outlet at top (copper current collectors were used to connect carbon compound electrodes)

Table 1. Summary of experimental conditions for full cells

\begin{tabular}{|c|c|c|c|}
\hline Flow & Current density $\left[\mathrm{mA} \mathrm{cm}^{-2}\right]$ & End of charge $\left[\mathrm{mAh} \mathrm{cm}^{-2}\right]$ & End of discharge [V] \\
\hline $44 \mathrm{~mL} / \mathrm{min}$ & $20-40$ & 20 & 1.1 \\
\hline
\end{tabular}

Table 2. Summary of experimental conditions for Hull-cell experiments

\begin{tabular}{cccc}
\hline Stirring [rpm] & Current [A] & Time $[\mathrm{s}]$ & Counter electrode \\
\hline 450 & 5 & 90 & Pure lead \\
\hline
\end{tabular}

\section{Lead electrodeposition}

Metal electrodeposition is widely utilized and procedures are very well known and documented. One very common phenomenon during lead electrodeposition is dendritic 
growth, which is one major failure mechanism not only for lead-acid batteries, but also for zinc-air or lithium-ion batteries. It has been shown that lead deposits in its dendritic form when the growth rate is limited by the diffusion of ions from the solution to the interface [16]. Local depletions of lead ions are very difficult to avoid, even with a very controlled and intense flow of fresh electrolyte to the cell. This is the case as the electrode itself changes its shape during electrodeposition and thus a functional flow field is rather difficult to design. Especially under the conditions of current densities of more than $40 \mathrm{~mA} \mathrm{~cm}{ }^{-2}$, which are desired for economic use of SLFB cells, local imbalances of the electrolyte concentration can occur quickly, leading to dendrite formation. Dendrites in a SLFB cell not only can penetrate the inter electrode gap and cause short circuits between active masses, but also these dendritic crystals do not adhere well to the electrode surface and may be flushed from the cell and accumulate in the reservoir. Therefore, these particles may not be available for the subsequent discharge reaction. Such an imbalance between the two active masses lead to an unbalanced build-up of active masses on one of the electrodes and thus eventually to cell failure.

Additives. A variety of additives are known to have the ability to suppress dendritic growth. However, due to the function of such additives, this always comes at the cost of efficiency. This has to be kept in mind particularly when utilizing such additives for a battery, where efficiency is a key factor. There is a variety of additives known and utilized in the lead electroplating industry to deposit lead as shiny coatings for electronic components such as solder pads. Commercial lead electroplating solutions, however, may cause problems in SLFB systems, such as strong inhibition of the positive electrode. As industrial electroplating focuses on the bare metal or its alloys, deposition of oxide layers is usually not desired. Indeed, industrial electroplating baths usually even include reducing agents, which may react with the positive electrode during its plating and under certain circumstances even completely inhibit $\mathrm{PbO}_{2}$ electrodeposition. Consequently, these solutions are of little use for SLFB systems and new dendrite inhibitors have to be found. One major concern of such additives indeed is the presence of the $\mathrm{PbO}_{2}$ electrode in the cell, as $\mathrm{PbO}_{2}$ is known to be a strong oxidizer for organic compounds, while the organic additive is oxidised, the $\mathrm{PbO}_{2}$ electrode is being reduced and thus consumed. The additives necessary for deposition of smooth metallic layers are called expanders and brighteners. Expanders such as lignin-derivates or succinic acid are commonly employed in lead-acid batteries to ensure an even crystal growth of lead during charge. They have an effect that is more related to shifting the crystal size from growth of larger crystals to smaller, well distributed crystals and not so much inhibition of dendritic growth as such. Nevertheless, these expanders work well in SLFB cells to maintain an even crystal growth and thus inhibit the creation of large crystals that are prone to dendritic growth. Pletcher et al. [11] have performed an extensive research on additives for SLFB cells and identified a few possible candidates that are very suitable to create smooth and even deposits for lead. From the selection presented, however, the best solution seems to be the use of Hexadecyltrimethylammonium (HDTMA) cations, as these help to form well adhering layers with high coulombic efficiencies of $93 \%$ at $20 \mathrm{~mA} \mathrm{~cm}^{-2}$, while compared to Lignin and Triton X-100, HDTMA performed in a similar way, but it is not as easily oxidized by the $\mathrm{PbO}_{2}$ present in the cell. For an economic operation of a cell, however, at least a current density of $40 \mathrm{~mA} \mathrm{~cm}^{-2}$ is desired.

Pulse plating. Pulse plating is another approach of reducing dendritic growth by applying a short pulse of current $\left(T_{\mathrm{ON}}\right)$, followed by a period of rest $\left(T_{\mathrm{OFF}}\right)$, and sometimes even a short discharge $\left(T_{\mathrm{DISC}}\right)$. The total time is described as $T_{\mathrm{TOT}}$ (eq. 2$)$. By applying for example a pulse with $T_{\mathrm{ON}}=100 \mathrm{~ms}$ followed by $T_{\mathrm{OFF}}=200 \mathrm{~ms}$ the electrodes are being allowed some time to equilibrate in between the current pulses, thus 
reducing polarisation of the electrodes and allowing diffusion as well as convection of ions to the electrode surface. The term duty cycle is being used for a factor of the applied current $T_{\mathrm{ON}}$ vs. the total pulse duration $T_{\text {TOT }}$ as shown in eq. (3):

$$
\begin{gathered}
T_{\mathrm{TOT}}=T_{\mathrm{ON}}+T_{\mathrm{OFF}}+T_{\mathrm{DISC}} \\
\text { Duty cycle }=\frac{T_{\mathrm{ON}}}{T_{\mathrm{TOT}}}[\%]
\end{gathered}
$$

As local ionic depletions are one of the major causes for dendritic growth [16], giving the solution time to replenish in between short charge pulses is a promising approach for dendrite inhibition. However, it has to be borne in mind that pulse charging is electrically much more demanding than a constant current charge as much more sophisticated charge algorithms and electrical components are being utilized. Another factor to consider is that the same overall capacity still is to be applied within the same timeframe in order to have a beneficial effect. Thus, the pulse currents need to be a multiple of the currents applied for a constant charge. For example, a pulse with $T_{\mathrm{ON}}=100 \mathrm{~ms}$ and $T_{\mathrm{OFF}}=200 \mathrm{~ms}$ and a corresponding duty cycle of $33.3 \%$ needs to be at least three times the current of the equivalent constant charge current. There is also the opportunity of a short polarity reverse, called $T_{\mathrm{DISC}}$ during which the electrodes are discharged during a very short time interval. This strategy may be beneficial for electrode structures that are very prone to dendrite formation, as it increases the anti-dendrite effect. Since dendritic crystals are usually closer to the counter electrode, they generally have a lower ionic resistance than the bulk electrode and thus they can be discharged preferably to the bulk electrode. Such discharge pulses usually smooth out very dendritic structures, but also further lower the duty cycle and increase pulse current demands. The duty cycle calculated from a pulse algorithm including a discharge, may be described by eq. (4), given that the current of $T_{\mathrm{DISC}}$ is equivalent to $T_{\mathrm{ON}}$ but only reversed in polarity:

$$
\text { Duty cycle }=\frac{T_{\mathrm{ON}}-T_{\mathrm{DISC}}}{T_{\mathrm{TOT}}}[\%]
$$

Cell efficiency. For electrochemical cells, efficiency is one of the most important factors. Efficiency not only directly affects the amount of energy that can be stored and retrieved from a battery, but also any loss in efficiency is usually emitted by the system in terms of heat. While an increasing temperature of the battery can negatively affect performance, it can, for some systems, even create a hazard of thermal runaway. This may be the case when an increase in temperature lowers efficiency and thus emits more heat that cannot be removed from the system, until a critical temperature is reached and the system catches fire or even explodes. Efficiencies of electrochemical cells are usually calculated using three different characteristics. Coulombic efficiency takes into account charge transfer ratio between discharge $(Q)$ and charge $\left(Q_{0}\right)$ reaction:

$$
\eta_{\mathrm{C}}=\frac{Q}{Q_{0}}
$$

Voltaic efficiency, which takes into account potential ratio between discharge $(U)$ and charge $\left(U_{0}\right)$ reaction:

$$
\eta_{\mathrm{U}}=\frac{U}{U_{0}}
$$


and energy efficiency, which is a combination of coulombic and voltaic efficiency, resulting in the relation of overall energy between the discharge $(W)$ and charge $\left(W_{0}\right)$ reaction:

$$
\eta_{\mathrm{W}}=\frac{W}{W_{0}}
$$

\section{RESULTS AND DISCUSSION}

It has been shown by Hull-cell experiments (Figure 3), that without the use of additives, lead coatings may be deposited up to a current density of approx. $75 \mathrm{~mA} \mathrm{~cm}^{-2}$ in a non-dendritic way. Above these current densities, clearly dendritic crystals were observed. The addition of $5 \mathrm{mmol} / \mathrm{L}$ HDTMA to the electrolyte increases the non-dendritic current density to more than $250 \mathrm{~mA} \mathrm{~cm}^{-2}$. Dendritic growth then is only seen on the very edge of the Hull-cell sheet, where not only extremely high current densities are achieved, but also edge effects play an increasing role. In addition, the deposit quality seems to be considerably enhanced, even at lower current densities, leading to a matte and uniform lead deposit. This leads to the conclusion that HDTMA is a very suitable brightener for the use in SLFB cells.

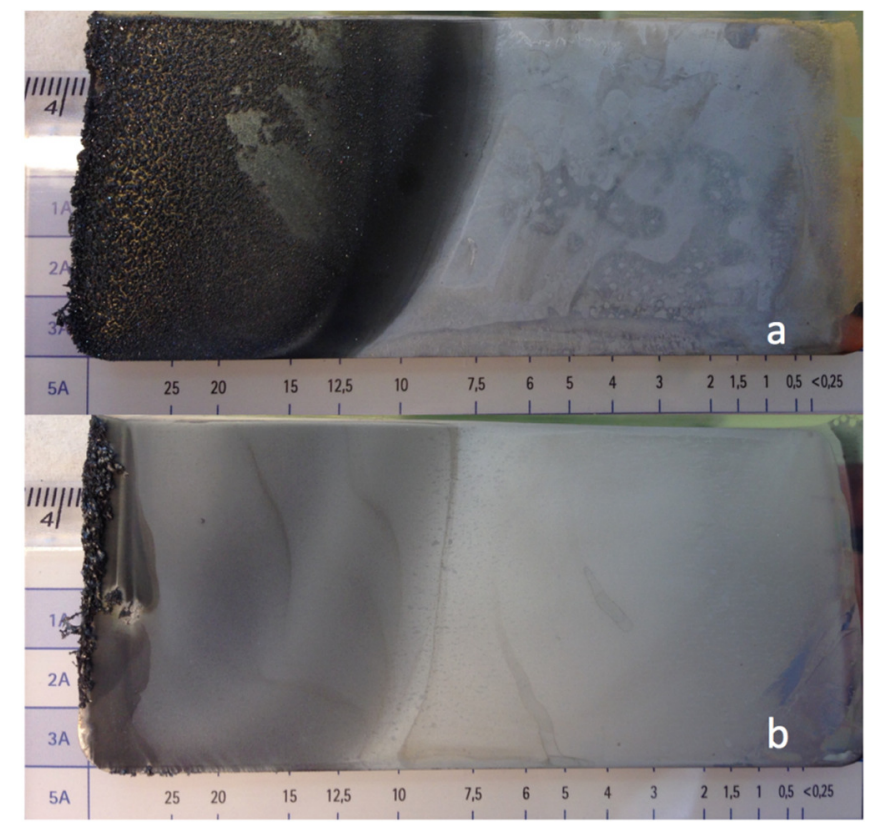

Figure 3. Comparison of Hull-cell experiments where: is a cell without (a) additives and is a cell with $5 \mathrm{mmol} / \mathrm{L}$ HDTMA added to the electrolyte (b) (the shown scale is in $\mathrm{A} \mathrm{dm}^{-2}$ as usual for electroplating)

In full cells, according to Hull-cell experiments, uniform deposits should be obtained without the need of any additives at current densities of up to $40 \mathrm{~mA} \mathrm{~cm}{ }^{-2}$ (Figure $3 \mathrm{a}$ ). Full cell experiments, however, showed that it was impossible to run a cell at $40 \mathrm{~mA} \mathrm{~cm}^{-2}$ as dendrites would short the cell within the first few cycles. Even at $20 \mathrm{~mA} \mathrm{~cm}^{-2}$ which was chosen as an alternative, dendritic structures were formed very early during cycling experiments. Usually, these dendritic structures would accumulate over as few as 20 cycles and short the cell, leading to a cell failure. It can be seen from the cycle diagram of a full cell at $20 \mathrm{~mA} \mathrm{~cm}^{-2}$ with charge duration of $1 \mathrm{~h}$ and discharge to $1.1 \mathrm{~V}$ (Figure 4) that dendrites develop starting in cycle $16(29 \mathrm{~h})$, creating shorts and discharge periods getting significantly shorter after cycle $22(40 \mathrm{~h})$. The relation of the charge capacity vs. the very short discharge capacity shows that most of the charge energy is consumed by 
the current flowing through the dendrites shorting the cell, and that there is only very little energy being converted to $\mathrm{Pb}$ and $\mathrm{PbO}_{2}$, as it is shorted out. Analysis of the cell after cycling [Post Mortem Analysis (PMA)] shows heavily dendritic lead deposits leading to shorts (Figure 5). The fact that dendritic growth within the full cell develops, despite the Hull-cell experiments predicting non-dendritic deposits, is being attributed to the non-optimized flow pattern within the test cells being used. Possibly the very basic inlet/outlet design in combination with the cylindrical cell used, promotes stationary areas within the cell where depletion of electrolyte occurs, leading to dendritic growth.

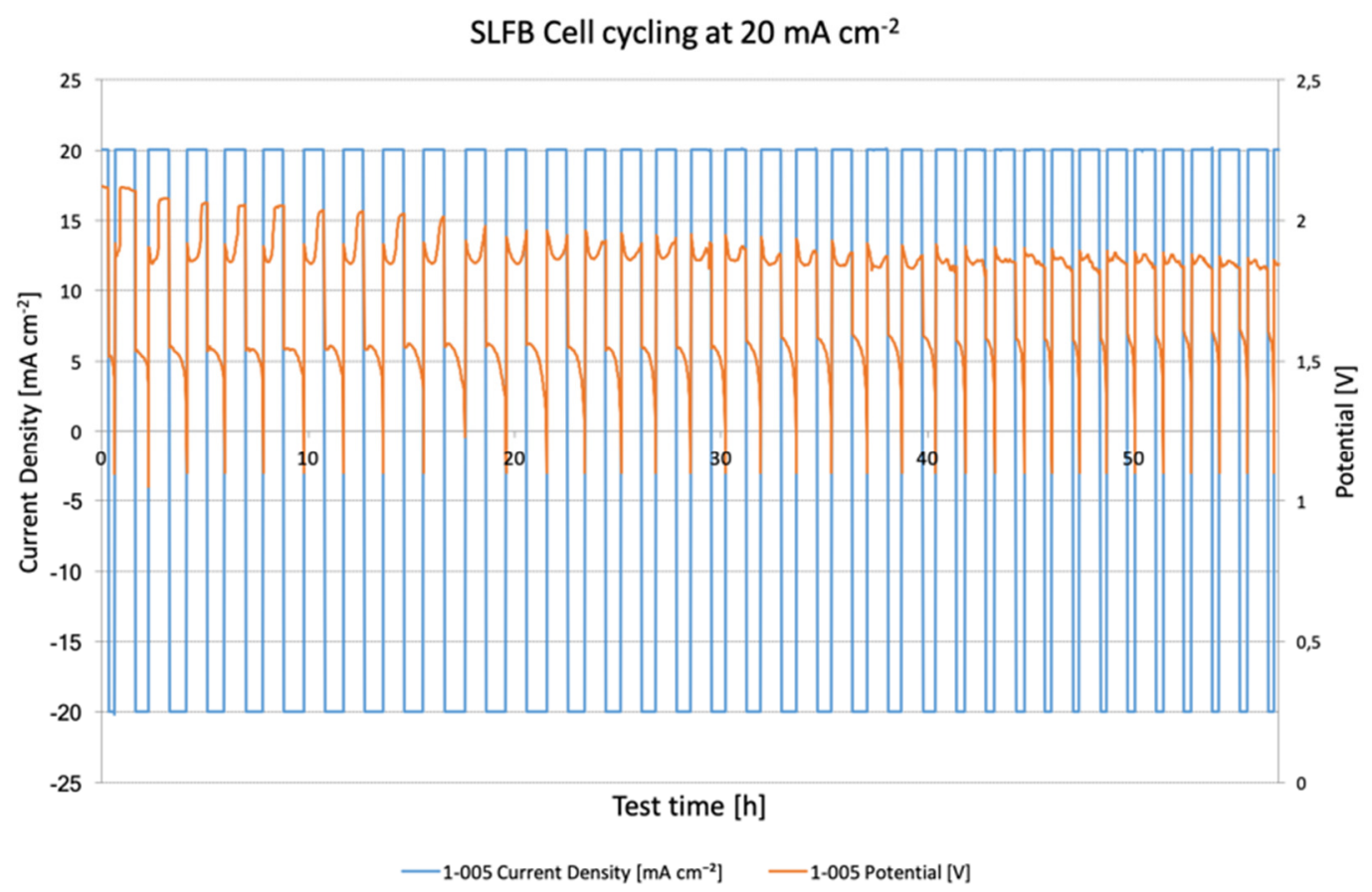

Figure 4. Cycle diagram of cell cycled at $20 \mathrm{~mA} \mathrm{~cm}^{-2}$ with $1 \mathrm{~h}$ charge and discharge to $1.1 \mathrm{~V}$, after

22 cycles $(40 \mathrm{~h})$, discharge periods get significantly shorter and charge potentials show micro-shorts (visible as drop in potential), leading to the conclusion that the cell is shorted due to dendrites (cycling was performed over a period of 58 hours)

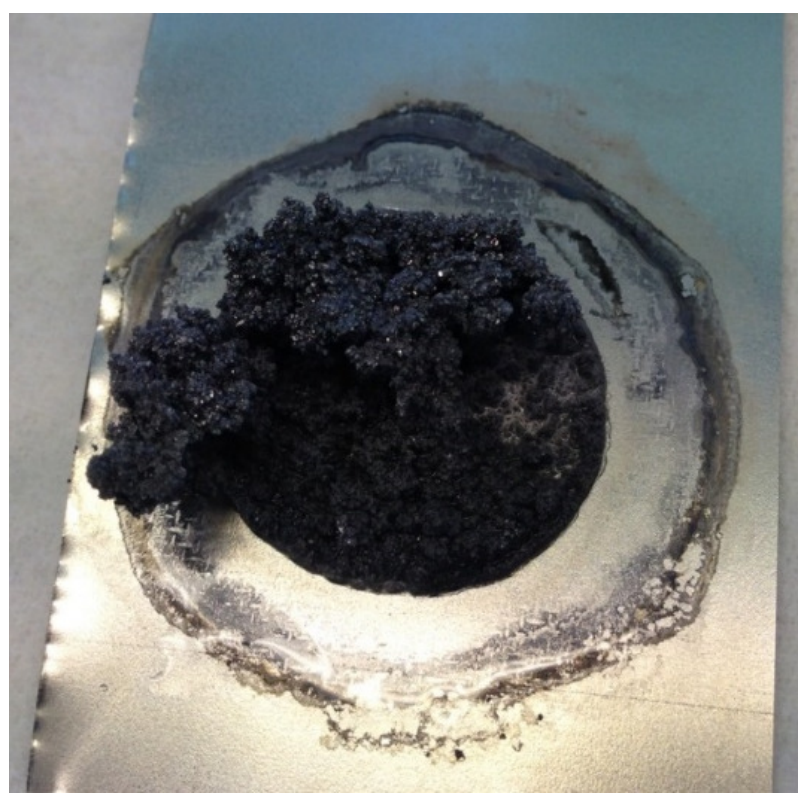

Figure 5. Dendritic structures on negative electrode after 33 charge and discharge cycles (shown in Figure 4) 
An equivalent cell with the addition of HDTMA as an additive, was cycled for a period of more than 4,000 hours and efficiencies were calculated for each cycle. The cell shown was cycled for more than 7,000 cycles at a current density of $40 \mathrm{~mA} \mathrm{~cm}{ }^{-2}$ but with the same capacity, so charge duration was 30 minutes. After an initial formation phase of approx. six cycles, voltaic and energy efficiencies for the cell are usually between $70 \%$ and $80 \%$, whereas coulombic efficiencies are usually above $90 \%$. Once the cell has stabilized after approx. 40-50 cycles, coulombic efficiencies rise to even more than $97 \%$ (Figure 6). This is especially notable, as Pletcher et al. [11] have determined the coulombic efficiency of a cell with HDTMA to be at $93 \%$ for a current density of $20 \mathrm{~mA} \mathrm{~cm}{ }^{-2}$. However, it is still unclear what happens during that initial stabilisation phase. The pronounced spikes in voltaic efficiency every 100 cycles are due to electrode stripping and reconditioning in order to remove accumulated deposits from the electrode surfaces by deep-discharging the cell to $0 \mathrm{~V}$. There is one additional spike in energy and coulombic efficiency visible at 290 cycles, which most likely is related to an operating error during testing. The strategy of stripping the cell after a specified number of cycles allows the cell to theoretically run for an infinite time, as the electrode surfaces are renewed each time a stripping reaction is performed and the cell restarts from its initial configuration. From a diagram showing a selection of the individual cycles (Figure 7), it can be seen that there is virtually no change in charge potential once the cell has stabilized to cycle 7,000. There is a slight deviation in discharge behaviour from cycles prior to 1,000 and cycles after 1,000. This also explains the shift in potential- and energy efficiency, observed in Figure 6. The cell had to be eventually stopped after 7,012 cycles, as one of the electrodes was not completely inert and subject to corrosion. In order to achieve the highest possible adhesion of anode active mass onto the electrode substrate, antimonial lead was chosen for an electrode material, as adhesion of lead on lead is expected to be superior to most other materials. However, antimonial lead is not fully corrosion resistant to MSA electrolyte and this has led to some corrosion effects, leading to penetration of electrolyte through the electrode and thus a leakage of the flow-cell.

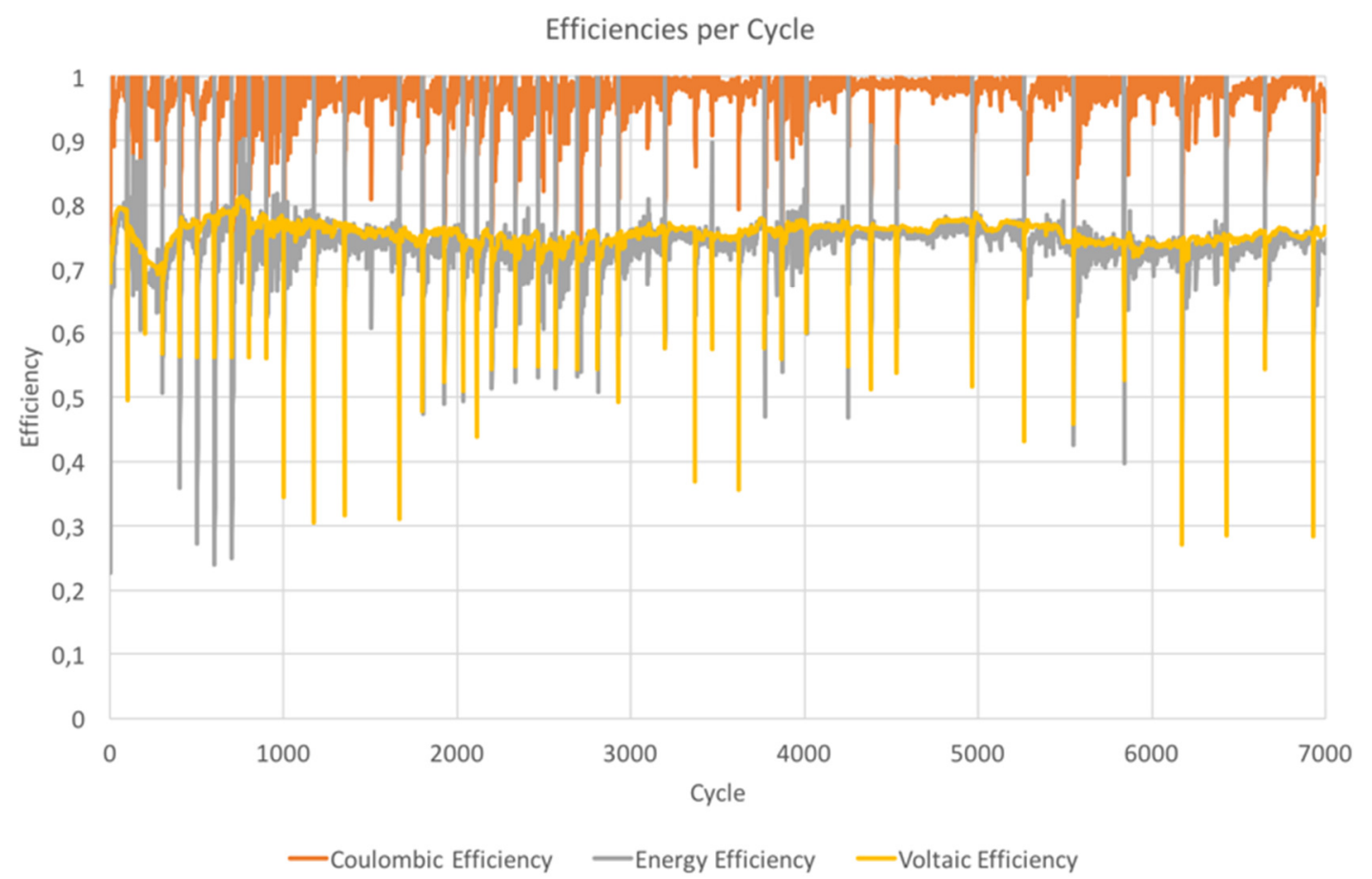

Figure 6. Calculated efficiencies for each cycle from 1 to 7,000, Coulombic efficiencies are usually beyond $90 \%$, whereas voltaic and energy efficiencies are usually greater than $70 \%$ [eq. (5-7)] 
While this cell does not include pulse plating yet, it is expected that the performance can be further improved by utilizing pulses of $60 \mathrm{~mA} \mathrm{~cm}^{-2}$ at a duty cycle of $1 / 3$ $\left(T_{\mathrm{ON}} / T_{\mathrm{OFF}}=100 \mathrm{~ms} / 200 \mathrm{~ms}\right)$. Experiments on pulse plating have shown that this is a favorable pattern for lead electrodeposition. While Constant Current (CC) experiments yielded a high degree of crystallinity on the microscale (face-centered cubic crystals of 1-2 $\mu \mathrm{m}$ diameter), the overall structure of the electrode is rather amorphously arranged in lumps of 20 to $30 \mu \mathrm{m}$ diameter (Figure 8). Notably, there are flake-like structures above the mentioned structures, covering approximately $50 \%$ of the entire surface. It can be seen that the layers deposited with CC are rather thick, and thus have a high degree of porosity. Pulse Current (PC) experiments, however, showed a very high degree of crystallinity. These crystals are in the range of $20-30 \mu \mathrm{m}$, whereas the flake like structures are not evident at all. With larger magnification, it can be seen that the single crystals also are more pronounced and up to three times the size of crystals deposited with CC (Figure 9). The needle-like crystals seen in these pictures are related to insufficient flushing of the prepared samples and are very characteristic of lead methanesulfonate. Adhesion tests showed that these structures show a better adhesion to the electrode substrate and thus increased mechanical stability.

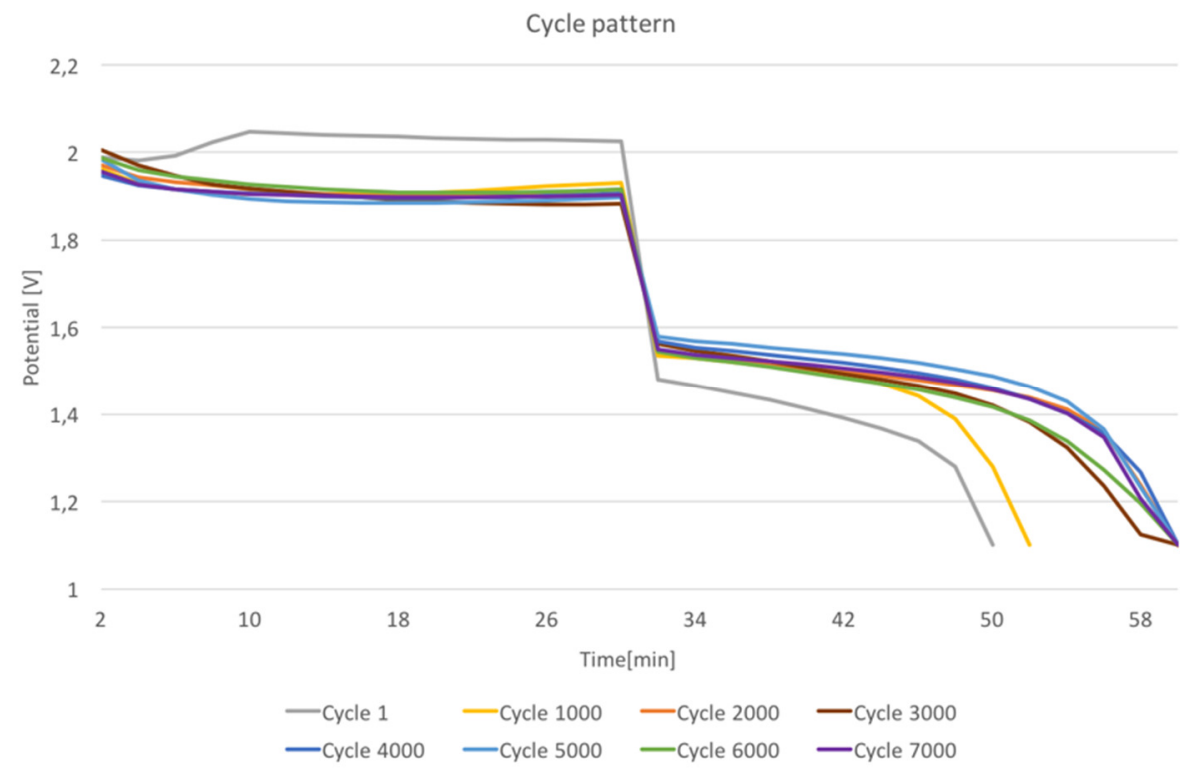

Figure 7. Overlay of cycle patterns, showing very constant potential behaviour over a wide range of cycles

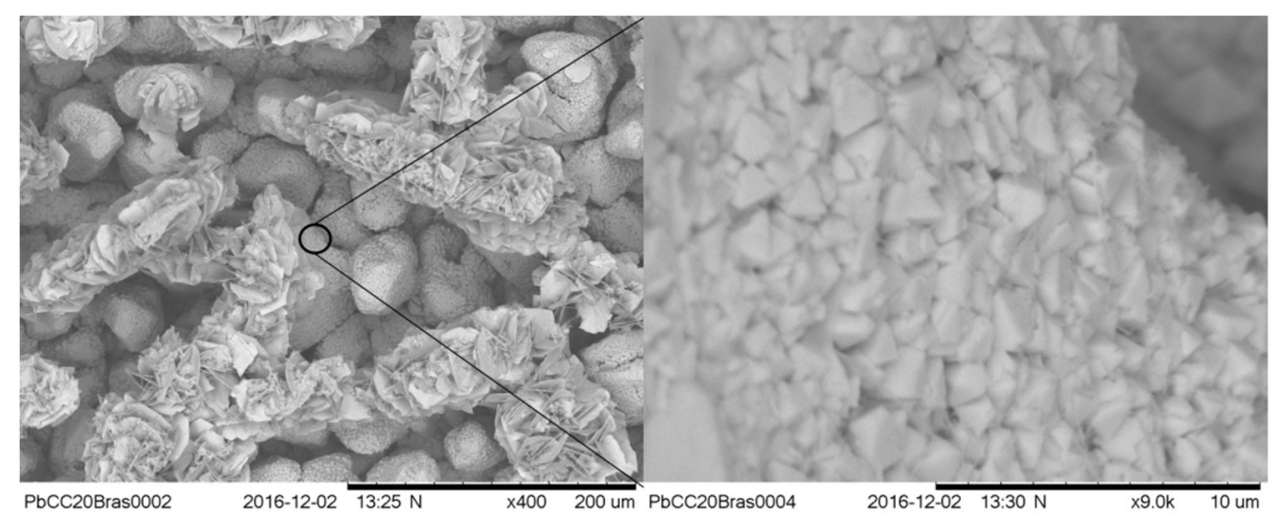

Figure 8. SEM pictures of a cell charged at a constant current density of $20 \mathrm{~mA} \mathrm{~cm}{ }^{-2}$, left hand picture is at $400 \times$ magnification, right hand at 9,000× magnification, total charge capacity is $20 \mathrm{mAh} \mathrm{cm}^{-2}$ 


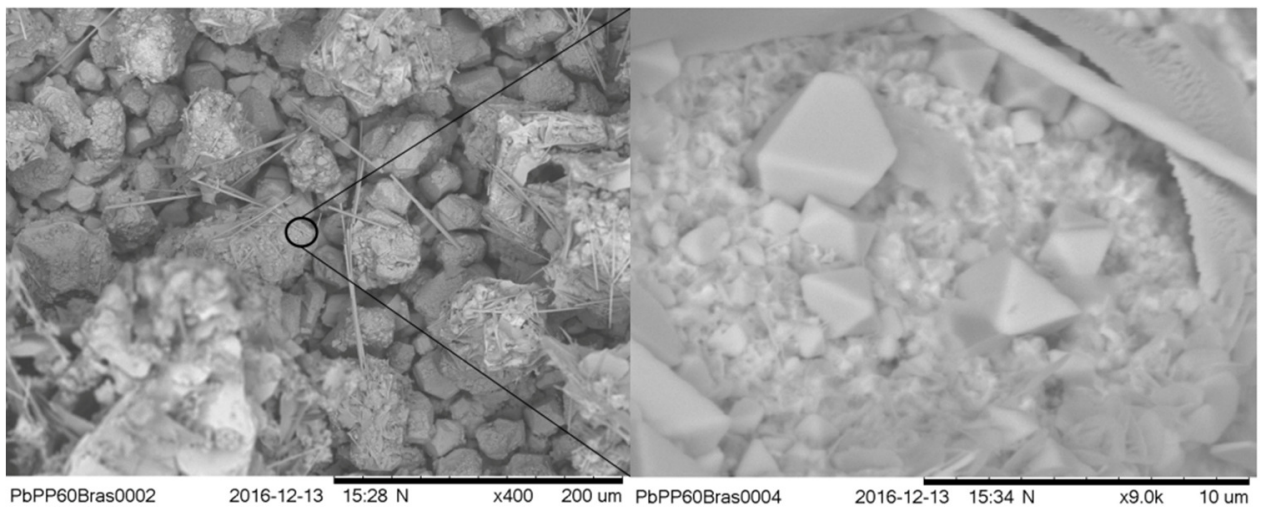

Figure 9. SEM pictures of a cell charged with pulse current algorithm of $60 \mathrm{~mA} \mathrm{~cm} \mathrm{~cm}^{-2}$ for $100 \mathrm{~ms}$, followed by $200 \mathrm{~ms}$ rest for equilibration, resulting in an averaged current density of $20 \mathrm{~mA} \mathrm{~cm}{ }^{-2}$, left hand picture is at $400 \times$ magnification, right hand at 9,000× magnification, total charge capacity is $20 \mathrm{mAh} \mathrm{cm}-2$

\section{CONCLUSION}

It has been shown that SLFB flow-cells with HDTMA as an anti-dendrite additive show a high cycle life of more than 7,000 cycles at $40 \mathrm{~mA} \mathrm{~cm}^{-2}$ with high efficiencies and without intervention to the system. These experimental setups included a periodic electrode renewal by shorting both electrodes to $0 \mathrm{~V}$ and thus fully discharge the cell, leading to fresh electrode substrates for successive cycles. Pulse plating algorithms are expected to further increase the time span between electrode reconditioning as it has been shown that they can further increase plating qualities for electrodeposited active masses, particularly for the anode. These characteristics combined with the inherent safety of the system make SLFB a very promising candidate for energy storage applications. However, the limiting factor is still the electrode substrate, which has been a sheet of antimonial lead for the experiments presented in this publication. This material was subject to corrosion effects when cycled for a prolonged time and thus alternative materials are still a subject of research.

\section{REFERENCES}

1. N. R. C. Committee for the National Academies Summit on America's Energy Future, The National Academies Summit on America's Energy Future: Summary of a Meeting, National Academies Press, Washington, D. C., USA, 2008.

2. Zhang, C. P., Sharkh, S. M., Li, X., Walsh, F. C., Zhang, C. N. and Jiang, J. C., The Performance of a Soluble Lead-acid Flow Battery and its Comparison to Static Lead-acid Battery, Energy Conversion and Management, Vol. 52, No. 12, pp 3391-3398, 2011, https://doi.org/10.1016/j.enconman.2011.07.006

3. Gernon, M. D., Wu, M., Buszta, T. and Janney, P., Environmental Benefits of Methanefsulfonic Acid. Comparative Properties and Advantages, Green Chemistry, Vol. 1, No. 3, pp 127-140, 1999, https://doi.org/10.1039/a900157c

4. Oury, A., Kirchev, A., Bultel, Y. and Chaintet, E., $\mathrm{PbO}_{2} / \mathrm{Pb}^{2+}$ Cycling in Methanesulfonic Acid and Mechanisms Associated for Soluble Lead-acid Flow Battery Applications, Electrochimica Acta, Vol. 71, pp 140-149, 2012, https://doi.org/10.1016/j. electacta.2012.03.116

5. Meng, Y., Verde, M., Carroll, K. J., Wang, Z. and Santhrum, A., Achieving High Efficiency and Cyclability in Inexpensive Soluble Lead Flow Batteries, Energy Environ. Sci., Vol. 6, No. 5, pp 1573-1581, 2013, https://doi.org/10.1039/c3ee40631h 
6. Skyllas-Kazacos, M., Kasacos, G., Poon, G. and Verseema, H., Recent Advances with UNSW Vanadium-based Redox Flow Batteries, Int. J. Energy Res., Vol. 34, No. 2, pp 182-189, 2010, https://doi.org/10.1002/er.1658

7. Pletcher, D., Wills, R. and Hazza, A., A Novel Flow Battery: A Lead Acid Battery Based on an Electrolyte with Soluble Lead(II) Part I, Preliminary Studies, Phys. Chem. Chem. Phys., Vol. 6, No. 8, pp 1773-1778, 2004, https://doi.org/10.1039/b401116c

8. Pletcher, D. and Wills, R., A Novel Flow Battery: A Lead Acid Battery Based on an Electrolyte with Soluble Lead(II) Part II, Flow Cell Studies, Phys. Chem. Chem. Phys., Vol. 6, No. 8, pp 1779-1785, 2004, https://doi.org/10.1039/b401116c

9. Pletcher, D. and Wills, R., A Novel Flow Battery-A Lead Acid Battery Based on an Electrolyte with Soluble Lead(II): III. The Influence of Conditions on Battery Performance, Journal of Power Sources, Vol. 149, pp 96-102, 2005, https://doi.org/10.1016/j.jpowsour.2005.01.048

10. Pletcher, D., Wills, R. and Hazza, A., A Novel Flow Battery-A Lead Acid Battery Based on an Electrolyte with Soluble Lead(II): IV. The Influence of Additives, Journal of Power Sources, Vol. 149, No. 1, pp 103-111, 2008, https://doi.org/10.1016/j.jpowsour.2005.01.049

11. Pletcher, D., Zhou, H., Kear, G., Low, C. T. J., Walsh, F. C. and Wills, R. G. A., A Novel Flow Battery-A Lead-acid Battery Based on an Electrolyte with Soluble Lead(II): V. Studies of the Lead Negative Electrode, Journal of Power Sources, Vol. 180, No. 1, pp 621-629, 2008, https://doi.org/10.1016/j.jpowsour.2008.02.024

12. Pletcher, D., Zhou, H., Kear, G., Low, C. T. J., Walsh, F. C. and Wills, R. G. A., A Novel Flow Battery-A Lead-acid Battery Based on an Electrolyte with Soluble lead(II) Part VI. Studies of the Lead Dioxide Positive Electrode, Journal of Power Sources, Vol. 180, No. 1, pp 630-634, 2008, https://doi.org/10.1016/j.jpowsour.2008.02.025

13. Li, X., Pletcher, D. and Walsh, F. C., A Novel Flow Battery: A Lead Acid Battery Based on an Electrolyte with Soluble Lead(II): Part VII. Further Studies of the Lead Dioxide Positive Electrode, Electrochimica Acta, Vol. 54, No. 20, pp 4688-4695, 2009, https://doi.org/10.1016/j.electacta.2009.03.075

14. Li, X., Collins, J., Kear, G., Low, C. T. J., Pletcher, D., Tangirala, R., Stratton-Campbell, D., Walsh, F. C. and Zhang, C., A Novel Flow Battery: A Lead Acid Battery Based on an Electrolyte with Soluble Lead(II) Part VIII. The Cycling of a $10 \mathrm{~cm}$ $\times 10 \mathrm{~cm}$ Flow Cell, Journal of Power Sources, Vol. 195, No. 6, pp 1731-1738, 2010, https://doi.org/10.1016/j.jpowsour.2009.09.044

15. Li, X., Collins, J., Pletcher, D., Tangirala, R., Stratton-Campbell, D., Walsh, F. C. and Zhang, C., A Novel Flow Battery: A Lead Acid Battery Based on an Electrolyte with Soluble Lead(II). Part IX: Electrode and Electrolyte Conditioning with Hydrogen Peroxide, Journal of Power Sources, Vol. 195, No. 9, pp 2975-2978, 2010, https://doi.org/10.1016/j.jpowsour.2009.10.109

16. Sun, M., Liao, H-G., Niu, K. and Zheng, H., Structural and Morphological Evolution of Lead Dendrites during Electrochemical Migration, Nature Scientific Reports, Vol. 3, Article Number 3227, 2013, https://doi.org/10.1038/srep03227 